\title{
DE ECONOMIST EN HET SOCIALE VRAAGSTUK
}

Door Prof. Dr J. TINBERGEN

Honderd jaargangen van een tijdschrift weerspiegelen vele ontwikkelingen tegelijk. In de eerste plaats zijn het de feiten zelf van de maatschappelijke ontwikkeling, die zich doen gelden. Daarnaast de doelstellingen en opvattingen van het tijdschrift, of beter, zijn redactie. De laatste op hun beurt echter ondergaan ten dele de veranderingen, die in de opvattingen in het algemeen bestaan, al behoeven zij zich daarbij uiteraard niet nauwkeurig aan te sluiten. Ten slotte zal elk tijdschrift het stempel dragen van de bijzondere persoonlijkheden, die hebben meegewerkt of leiding hebben gegeven bij de redactie. Deze vier verschillende invloeden zullen niet altijd gemakkelijk uiteen te houden zijn, Wanneer in het volgende getracht wordt bepaalde eigenaardigheden in de ontwikkeling van het tijdschrift toe te schrijven aan een of meer dezer vier dooreengestrengelde factoren, dan zal dat voor een belangrijk gedeelte min of meer juist kunnen geschieden op grond van kennis uit andere bronnen, maar het zal er ook weleens naast zijn.

Beginnen wij ons verslag met enkele opmerkingen over de maatschappelijke feiten. Ten tijde van de oprichting van De Economist was de toestand van de arbeidersklasse in Nederland slecht te noemen. De oprichting van De Economist was daarop een min of meer verwijderde reactie. Voor wie deze maatschappelijke feiten niet steeds voor ogen heeft is het goed aan enkele ervan te herinneren. Men vindt er in de oudere jaargangen overvloedig materiaal over. Wij lezen van een zuigelingensterfte van één à twee op de zes pasgeborenen. Van een arbeidsduur, die voor volwassenen 17 uur bedroeg. De kinderarbeid was iets heel gewoons en hun arbeidstijd was ,slechts" 12 uur. De zorg voor de arbeiders was zeer gering. Een typisch zijlichtje wordt hierop geworpen door het feit, dat bv. de toenmalige locomotieven (evenals de voorbalcons van de later optredende electrische trams) open waren. Een ander zijlichtje verschaft het met de lange werktijd samenhangende verschijnsel, dat de lonen veelal 
uitgekeerd werden des Zaterdagsavonds om 9 uur, waarna dan nog alle ịkopen gedaan moesten worden. Juist zulke willekeurig gekozen illustraties geven wellicht een levendiger voorstelling omtrent de toestanden van toen dan cijfers. Ook de geestelijke toestanden waren niet bepaald bloeiend te noemen, hetgeen wellicht geillustreerd mag worden met de mededeling, dat één op de vier of vijf miliciens niet kon lezen of schrijven. Het alcoholisme tierde welig.

In de eeuw, die De Economist thans bestrijkt, ontwikkelden zich deze toestanden, zoals wij weten, in het algemeen zeer gunstig en daarvan is de weerslag in het tijdschrift ook goed te vinden. Wellicht het beste op indirecte wijze door vergelijking met het heden, waarbij het in 1926 verschenen en uiteraard met veel aandacht besproken proefschrift van dr I. J. Brugmans de belangrijkste bijdrage zou kunnen verschaffen. Daarnaast weerspiegelt zich in ons tijdschrift de ontwikkeling van velerlei sociale verbeteringen; in de eerste plaats de opkomst van de werktijdenregeling, culminerend in een groot aantal beschouwingen over: de achturendag. Reeds in 1893 hield daarvoor Prof. Greven een pleidooi, mede op grond van de gunstige resultaten in bepaalde Engelse gevallen geboekstaafd. Dit belette schrijvers van minder vooruitstrevende aard niet om in 1920 of 1923 en 1924 nog zeer critisch te staan tegenover de toen werkelijkheid geworden achturendag. Onze scherpzinnige vrouwelijke collega, mejuffrouw van Dorp, herleeft hierbij in onze herinnering.

Een merkwaardige verandering manifesteerde zich in dezelfde eeuw ook in de houding van de arbeiders zelf. In de jaargang 1863 vinden wij vermeld, dat de arbeiders van Lancashire tijdens de grote katoenschaarste van de Amerikaanse burgeroorlog geen regeringssteun wensten, doch wel particuliere. Een ziekenfonds zou zijn opgericht tegen de zin der werklieden. Inzage der boeken, aangeboden door de werkgevers tijdens een staking in 1873, werd door de arbeiders afgewezen, ,omdat zij het toch niet begrepen". De vakbeweging zou hierin heel wat verandering brengen. De geschiedenis van de Engelse vakbeweging vindi reeds in 1894, naar aanleiding van het beroemde boek van Sidney en Beatrice Webb, grote aandacht in een uitvoerige boekbespreking door Pierson.

Ofschoon De Economist zelf in de laatste decennia veel minder ingesteld was op het weergeven van de toestand van de arbei- 
dersklasse, zou het niet moeilijk geweest zijn om aan de hand van de thans overvloedige gegevens betreffende de besteding van het arbeidersinkomen, en de even overvloedige gegevens betreffende werktijd en sociale verzekeringen, de fundamentele ommekeer vast te stellen, die in deze eeuw heeft plaats gevonden, voor een belangrijk gedeelte als gevolg van de sterk toegenomen kapitaalrijkdom en de activiteit van de vakbeweging. Bij een beschouwing van deze ontwikkeling zal men echter nooit over het hoofd mogen zien, dat de kapitaalrijkdom van Nederland vòor een eeuw zeer gering was in vergelijking tot de huidige. Het is bekend genoeg dat in de verdeling van het nationale inkomen tussen arbeiders en niet-arbeiders in de landen, waarover men gegevens bezit, niet eens zo'n grote verandering is gekomen. Het is in de eerste plaats de stijging van het totale inkomen, die het mogelijk gemaakt heeft de toestand van de arbeidersklasse te verbeteren. Daarnaast is voor de laaste decennia uiteraard ook de belastingheffing een punt van betekenis.

Doch gaan wij terug tot 1852. De Economist wilde bij zijn oprichting zijn: ,,een tijdschrift voor alle standen tot bevordering van de volkswelvaart door verspreiding van eenvoudige beginselen van staathuishoudkunde". Het werd, zoals men weet, opgericht en men kan zeggen in de eerste tijd voor een groot gedeelte geschreven door Mr J. L. de Bruyn Kops. De benadering van het sociale vraagstuk is in deze eerste jaren wel geheel anders dan tegenwoordig. Men zou zeggen bijna vanuit de hoek van de liefdadigheid. Het was echter juist de bedoeling van De Economist om hier de economische analyse haar plaats te geven. Uit de titels van vele bijdragen in de eerste jaargangen ziet men de sterk sociaal gerichte belangstelling van het tijdschrift wel zeer duidelijk. Er volgen hier enige: Armoede en werkhuizen; Armenbedeeling; Wat moet men aan de armen geven?; Wat moet het volk leeren?; De invloed van het jaar 1848 op de arbeiders in Frankrijk; Wasch- en badinrigtingen voor de arbeidersklasse; Slavernij in Nederland. De economische analyse, waarmede het tijdschrift het sociale vraagstuk wilde belichten, was uiteraard de economische analyse van die tijd, welke ondanks de sociale instelling der schrijvers toch in vele opzichten op de tegenwoordige generatie een sterk liberale indruk zou maken, al is het aan de andere kant waar, dat wij in de allerlaaste tijd hebben leren zien, dat sommige der als 
liberaal gekwalificeerde denkbeelden een zeer algemene economische betekenis hebben.

Er werd aldus in de eerste plaats gedacht aan voorlichting, beter onderwijs, verhoging van productiviteit, d.w.z. aan de middelen die rechtstreeks bijdragen tot verhoging van productie en scholing. Daarnaast werd eveneens gedacht aan de uitbreiding van sociale voorzieningen en coöperatie, ofschoon reeds bij een boekbespreking in 1876 van een zekere teleurstelling over de coöperatie sprake is. Alle aangelegenheden, de arbeidersbescheiming betreffende, hebben dan ook in het bijzonder in deze eerste jaargangen de volle aandacht. Hierin weerspiegelt zich vermoedelijk zeer duidelijk de persoonlijke belangstelling van de oprichter, die, zoals gezegd, zeer veel bijdragen voor zijn rekening nam. Geleidelijk aan slaagt hij er in, evenals zijn opvolgers, het tijdschrift meer te maken tot een vrije tribune, waaraan vertegenwoordigers van uiteenlopende richtingen hun medewerking verlenen. Blijk daarvan geven enige belangrijke bijdragen, die in een later stadium door vooraanstaande socialisten zijn geschreven, zij het ook dat de bijdragen van liberaal ingestelde schrijvers steeds op de voorgrond zijn gebleven. Dit zal men echter ook wel moeten zien als gevolg van het karakter van het tijdschrift, dat zich zeker niet ontwikkeld heeft als een ,tijdschrift voor alle standen", doch kennelijk tot een tijdschrift voor wetenschappelijk en meer in 't bijzonder wetenschappelijk-economisch. ingestelde lezers. Overeenkomstig de maatschappelijke ontwikkeling zowel als in overenstemming met de hierboven juist genoemde tendentie, veranderde de instelling van het tijdschrift in de loop van de eeuw van zijn bestaan wel duidelijk in de richting van het zuiver economische. Hierin mag men waarschijnlijk ook zien een uitdrukking van de steeds toenemende arbeidsverdeling in het denken en de steeds verdere splitsing van het wetenschappelijk terrein in deelwetenschappen. Een belangrijk gedeelte van de oorspronkelijke taak van De Economist zal zijn overgenomen door tijdschriften als Mens en Maatschappij, Het Gemenebest, en de wetenschappelijke organen van verschillende politieke en maatschappelijke groeperingen. Wat deze laatste betreft denken wij aan de reeks tijdschriften van socialistischen huize, beginnende met de Nieuwe Tijd, voortgezet door enerzijds de communistische tak van maandschriften en anderzijds de socialistische: De Socialistische Gids, en Socialisme en 
Democratie. Wij denken daarnaast aan het tijdschrift Econoinie, uitgaande van de Katholieke Economische Hogeschool en aan de tijdschriften van protestants-christelijken huize. Ook is een gedeelte van de stof, die men vroeger in De Economist kon vinden, met de uitbouw van het apparaat der sociale voorzieningen terecht gekomen in de aan dit apparaat gewijde meer. technische tijdschriften, die ook nogal eens van naam gewijzigd zijn en waarbij ik in het bijzonder wil noemen het Tijdschrift van de Nederlandse Werkloosheidsraad. Het behoeft ons dus niet te verbazen dat de inhoud van de artikelen in De Economist langzamerhand een andere geest is gaan ademen. Een andere kwestie is of als een geheel gezien het Nederlandse tijdschriftwezen, dat thans voor deze onderwerpen openstaat, niet een zekere overontwikkeling vertoont, waardoor zij alle min of meer financiëel noodlijdend schijnen te zijn. Een zekere concentratie zou ertoe kunnen leiden, dat de exploitatiebasis gezonder werd, dat artikelen van dubieuze kwaliteit ongepubliceerd zouden blijven en dat de artikelen van een uitstekende kwaliteit een grotere lezerskring zouden kunnen bereiken.

In welke mate manifesteerde zich in achtereenvolgende jaargangen van De Economist de ontwikkeling van de denkbeelden over sociale aangelegenheden, die de maatschappij als geheel te zien gaven? In de allereerste plaats ziet men deze ontwikkeling natuurlijk terug in de belangwekkende discussie met socialistische schrijvers. De opkomst van het socialisme toch is zeker het meest belangrijke sociale feit, dat in de beschouwde periode heeft plaats gevonden en waar zich het socialisme van de tweede helft der $19 \mathrm{e}$ eeuw overeenkomstig de denkbeelden van Marx als „wetenschappelijk" aandiende, in tegenstelling tot wat het in de voorafgaande phasen was, zal niemand verbaasd zijn juist in een tijdschrift als De Economist daarvan zekere sporen terug te vinden. Zoekt men ook hier weer naar de meest karakteristieke uiting van deze gedachtenwisseling, dan moet daartoe ongetwijfeld worden uitgekozen de discussie, die in het allereerste begin van de $20 \mathrm{e}$ eeuw, vrijwel dus in het midden van de door ons verslag gedekte periode, tussen de grote voorman van het wetenschappelijk economisch denken Pierson en de grote voorman van het socialistisch denken Wibaut plaats vond. Wat Piersons bijdrage betreft, ,Het waardeprobleem in de socialistische maatschappij" (1902), dit essay heeft ook de verdiende 
eer genoten te zijn vertaald en opgenomen in de bekende bundel van Hayek „Collectivist Economic Planning", welke schrijver, ofschoon de bundel eerst is verschenen in 1935, blijkbaar Piersons artikel nog steeds van grote waarde achtte. Terecht, en deze waarde moge er aanleiding toe zijn, dat ook hier op dit artikel nog wat nader wordt ingegaan.

In zijn duidelijke stijl, waarvan men als enig nadeel zou kunnen aanmerken dat zij de breedvoerigheid van de tijd niet geheel heeft vermeden, stelt Pierson allereerst aan de socialisten de eis: Weest duidelijk in de uiteenzetting Uwer bedoelingen. Hij onderscheidt n.l. drie soorten socialisme en merkt op, dat somtijds de socialisten in hun discussie bijna ongemerkt hun verdedigingsstellingen verleggen van de ene naar de andere soort, daaruit partijtrekkend, indien het debat zulks voor hen aantrekkelijk maakt. Ten aanzien van de werkloosheid b.v. merkt Pierson op, dat slechts de communistische variant der volledige planhuishouding de eer voor zich mag opeisen, dat zij de werkloosheid automatisch overwint. Bepaalde socialistische schrijvers, die zich om andere - en zeer aanvaardbare - redenen van de communistiche variant distanciëren, maken bij gelegenheid toch gaarne gebruik van deze eigenschap van ,het socialisme", wanneer het in hun kraam te pas komt. Ook omgekeerde gevallen doen zich voor. Vandaar Piersons eerste conclusie: laat elke socialist duidelijk zijn in het aangeven van zijn standpunt.

Verder zet schrijver uiteen dat economisten geen enkel vooroordeel tegen het socialisme hebben (misschien had hij moeten schrijven: behoren te hebben) en hij zelf geeft daarvan ongetwijfeld blijk. Hij heeft tot hoofdthema van zijn uiteenzetting de stelling gekozen, dat ook in de socialistische maatschappij het waardeprobleem uit de economische wetenschap zich op vele wijzen en in vele vormen zal voordoen en hij kiest daartoe zeer belangwekkende gevallen. Als eerste het geval van de handelscredieten in het internationaal verkeer. Aannemende dat er een aantal socialistische staten zullen ontstaan, stelt hij de vraag welke dezer staten de handelscredieten zullen leveren. In een zeer fraaie analyse herinnert hij er aan, dat in de toenmaals bestaande wereld dergelijke credieten in het bijzonder werden verleend, en dat is ook thans nog zo, door de kapitaalkrachtige landen en geeft hij ook aan waarom dit een goede arbeidsverdeling is. De oplossing van deze vraag is echter inderdaad een 
vraag van waardebepaling, n.l. het vergelijken van alternatieve aanwendingsmogelijkheden van de kapitalen, die elk dezer staten ter beschikking staan.

Als een tweede belangrijk voorbeeld kiest Pierson het vraagstuk van de vaststelling van het nationale inkomen van een socialistische staat en hij wijst er op, dat daarbij ook de waarde bepaald moet worden van de noodzakelijke afschrijvingein, voordat men dit vraagstuk kan oplossen. In nog een veelheid van andere situaties staat het niet anders: ook daar de noodzaak, het waardevraagstuk onder de ogen te zien. En passant vindt de schrijver nog aanleiding er op te wijzen, dat met het cumuleren van het kapitaal in zekere zin niet, zoals sommige socialisten het hebben willen zien, zijn macht groeit, want de versterkte concurrentie heeft integendeel de neiging dat de ene kapitaalbezitter de macht van de andere ondermijnt; men ziet dan ook dat de rentestand steeds daalt.

De handschoen, in dit artikel geworpen, wordt opgenomen door Wibaut, die in de eveneens buitengewone aantrekkelijke stijl, die hem eigen was, een evenzeer lezenswaardige bijdrage levert. Wellicht het meest opvallend in dit antwoord van de grote socialistische voorman is, dat hij in zo ruime mate aanleiding vindt het met Pierson eens te zijn. Met name erkent hij, dat nog lang een zeker „commercialisme”, zoals hij het noemt, nodig zal zijn en dat daarbij o.m. het instituut van de wissel niet gemakkelijk zal worden vervangen door een meer doelmatig apparaat. Wel ziet hij in het verschiet de mogelijkheid opdoemen van een meer planmatige oriëntering van de economische hande. lingen, wanneer de statistische voorlichting maar beter wordt. Daarbij zal z.i. de betekenis van de persoonlijke beoordeling van de economische toestand als basis voor practische beslissingen langzamerhand achteruitgaan. Men kan zich afvragen of niet de aard der gegevens die hier nodig zijn toch veelal nog een meer gedailleerde is dan ons de meeste statistieken kunnen leveren. Het punt, waarop Wibaut het duidelijkste stelling neemt tegenover Pierson, is dat waar hij bestrijdt dat alle inkomens een goede afspiegeling vormen van de productieve prestaties hunner trekkers. Daarbij kan hij natuurlijk met succes de vraag stellen of men meent dat alle vormen van speculatie mogen worden beschouwd als "dienstbetoon aan de maatschappij”, dat door deze om die reden beloond wordt. Dezelfde vraag is te 
stellen ten aanzien van bepaalde vormen van arbeidsloos inkomen, die met eigen spaaractiviteit niet meer te maken hebben.

$\mathrm{Na}$ deze ene grote ontmoeting met het socialisme volgen er, zoals men zal begrijpen, in de volgende decennia meerdere, en evenmin te verwonderen is het dat de voornaamste uitwendige aanleiding daartoe is gelegen in het verschijnen van het Socialisatierapport in 1920. Dit vormde begrijpelijkerwijze de aanleiding tot discussies over en weer, waaraan werd deelgenomen zowel door de felle opposanten, mejuffrouw Van Dorp en Bordewijk, als door de zeer veel rustiger en conciliantere figuur van Van Blom. Het is wel duidelijk dat in deze eerste jaren na de eerste wereldoorlog de hartstochten feller oplaaiden, dan sindsdien het geval is geweest, mogelijk ook zelfs feller dan tevoren, ofschoon dit laatste twijfelachtig lijkt. Alleen is van die hartstochten voordien in De Economist niet zoveel gebleken.

Uiteraard zijn de denkbeelden van het officiële socialisme niet de enige, die wijzigingen in de algemene opvattingen omtrent de economische inrichting onzer maatschappij vertegenwoordigen. Daarnaast vindt men de weerslagen van andere hervormingsvoorstellen, die in de loop van het beschouwde tijdsbestek naar voren zijn gebracht en als voorbeeld moge hier worden genoemd de aandacht door Spanjer bij herhaling gegeven aan de denkbeelden van F. Oppenheimer. Zoals men weet, heeft deze Duitse economist en socioloog veel sterker dan Marx de sociale spanningen in verband gezien met het grondbezit. De uitsluiting van een groot aantal personen van grondbezit maakt de mogelijkheid van de industrie-arbeider om zich tegen lage lonen te verdedigen geringer. De weg terug naar een zelfstandig bestaan op het land is des te minder mogelijk naarmate dit land in handen van grootgrondbezitters is. Deze theoreticus heeft dan ook alle maatschappelijke kwalen willen bestrijden niet zo zeer door socialisatie in het algemeen, als wel door de aantasting van het. grootgrondbezit. Hij verwacht dat daardoor in vele opzichten de toestand van werkelijk vrije concurrentie, zoals de theorie die kent, zou worden benaderd en is ook overigens deze vrije concurrentie juist goed gezind. Vandaar ook de naam van zijn stelsel: het liberaalsocialisme. Terwijl deze vorm van verbinding dezer twee termen aan invloed aanmerkelijk heeft ingeboet, is in de allerlaatste decennia een invloed gegroeid, die men desgewenst eveneens met deze naam zou kunnen aangeven. Het is 
de invloed van hen die, ofschoon socialist zijnde, in de werking van het prijsmechanisme, zoals beschreven door de economische theorie, zoveel nut zagen, dat ook zij van mening zijn geworden, dat in bepaalde opzichten eerder een herstel nodig zou zijn van deze werking dan een aantasting ervan. En ook, dat wellicht de voorwaarden, waaronder de prijsvorming zich in het algemeen voltrekt, nog meer zodanig kunnen worden gemaakt, dat aan de veronderstelling voldaan is, waarop de algemene economische theorie van de $19 \mathrm{e}$ eeuw stilzwijgend was gebaseerd, t.w. de volledige inschakeling van alle productiekrachten. De stroming, die wij hier bedoelen, worden gekenschetst door namen als Meade en Lerner. Uiteraard staan zij sterk onder de invloed van de niet-socialist Keynes en diens volgelingen. Hun denkbeelden vinden uiteraard ook hun echo in de bladzijden van De Economist en uiteraard eerst in zeer recente tijden. Op dit punt zal het nauwelijks nodig zijn het geheugen van onze lezers op te frissen. Volstaan moge worden met de opmerking, dat aan de werkgelegenheidspolitiek bij meer gelegenheden de nodige aandacht werd besteed. Overeenkomstig echter het meer gespecialiseerde karakter van ons tijdschrift in de laatste decennia zal men de belichting niet meer in dezelfde bewoordingen aantreffen, als waarmede het sociale vraagstuk in de eerste decennia na 1850 werd gesteld.

De stroming, die zich ook van de naam socialisme heeft meester gemaakt en zich nationaalsocialisme heeft genoemd, heeft in de jaargangen van De Economist slechts een zeer gering spoor nagelaten.

Er zijn echter ook belangrijke hervormingen bepleit en zelfs doorgevoerd, die, ofschoon ongetwijfeld door het socialisme tot activiteit gekomen, niettemin andere theoretische bases hebben gezocht en ten dele gevonden. Wij denken hierbij aan de reactie van politiek-kerkelijke zijde, die voor wat de katholieke tak betreft met de naam ",solidarisme" is aangegeven en veelal als uitgangspunt de pauselijke encyclieken kiest, of die door de protestants-christelijke, zij het minder duidelijk als onderieel van een algemeen stelsel, naar voren zijn gebracht en uitgewerkt. Hun is de belangstelling voor het rechtvaardig loon en voor een zekere samenwerking tussen arbeiders en ondernemers eigen, alsmede de voorkeur ook door vele socialisten gedeeld, voor een meer georganiseerde maatschappij, waarin dus aan het prijs- 
mechanisme zekere beperkingen worden opgelegd. De katholieke denkbeelden zijn uiteraard meestal niet in De Economist naar voren gebracht, omdat men zijn eigen organen daartoe koos, doch zij zijn, eveneens uiteraard, aan de inhoud van De Economist niet voorbijgegaan. Zo heeft Veraarts dissertatie aandacht getrokken in De Economist van 1912.

Van protestants-christelijke zijde is voor de gedachtengangen op economisch terrein in dit verband natuurlijk van bijzondere betekenis geweest het bekende artikel van F. de Vries: Coördinatie van het Verkeerswezen, 1933, waaruit blijkt dat een tevoren veelal als liberaal gekwalificeerde leidende economist zeer duidelijke beperkingen zag voor het gebied waarin vrije prijsvorming gewenst mag worden genoemd.

De ontwikkeling van de denkbeelden van het sociale vraagstuk gaat aldus meer in de richting van practische hervorming en van oplossing door een bewuste economische politiek van de sociale moeilijkheden waarvoor men kan geplaatst zijn. Zeer sterk heeft in dit opzicht natuurlijk de grote depressie haar stempel gezet op de vraagstukken en de denkbeelden. Interventie was toen aan de orde van de dag en het was niet te verwonderen dat de discussies in De Economist daarvan ook duidelijk de sporen droegen. Inmiddels is ook de arbeider zoveel meer gewoon burger geworden, dat men over zijn positie en zijn belangen schrijft op een wijze zoals men schrijft ovei anderen. De gedachte begint op te komen dat het sociale vraagstuk niet, slechts behoeft te betekenen een vraagstuk van arbeiders. Er komen andere groepen, die de aandacht meer van node hebben. $\mathrm{Er}$ is de bijzonder moeilijke positie van de kleine boer in crisistijd of de gepensionneerden in tijd van prijsstijging.

Er komt daarmede ook een einde aan het stellen van de maatschappelijke vraagstukken en de vraagstukken van economische politiek in scherpe, ,zwart-wit", tegenstellingen. De beide hoofdrichtingen hebben van elkaar en van de feiten geleerd. Slechts de werkelijke dogmatici blijven beweren dat of wel de grote depressie geheel is toe te schrijven aan het interventionisme of wel een ,gewone kapitalistische crisis" is, wat dat dan nog precies moge betekenen. Men leert te onderscheiden tussen de afzonderlijke, technische, natuurlijke en psychologische factoren die voor grote evenwichtsverstoringen aansprakelijk kunnen worden gesteld; men ziet mogelijkheden om deze factor waar 
nodig afzonderlijk ter zijde te stellen en men begint constructief te denken in de zin van direct-uitvoerbare regelingen die weliswaar het „kapitalistische stelsel" niet geheel terzijde stellen, doch het evenmin geheel in tact laten. Er verzamelt zich ervaring, goede en slechte, over het werken met verschillende insirumenten van economische politiek.

Parallel daarmede, ten dele er zelfs aan voorafgaand, ontwikkelt zich het inzicht dat er maatschappelijke noden zijn, zoals massale werkloosheid en oorlog, waarvan liberalen zowel als socialisten beide inzien dat zij voor de welvaart noodlottig zijn en dat er geestelijke stromingen opkomen, erger dan de kwalen die men daarmede wil bestrijden.

Ons beperkende tot de zuiver economische zijde van deze ontwikkeling kunnen wij stellen dat tegenover discussies in abstracto over de ontwikkeling op lange termijn van onze samenleving andere discussies de boventoon gaan voeren die betrekking hebben op kortere termijnen, voorlopige oplossingen, het openstaan voor nieuwe ervaringen zonder dat men van te voren al weet wat het beste is. De economen worden minder "Prinzipienreiter”, meer technici, er ontwikkelt zich steeds meer een empirisch ingestelde wijze van onderzoek; en tevens groeit er een grotere mate van saamhorigheid tussen de vakgenoten, die zich door gemeenschappelijke denkwijze verbonden weten. Zeer treffend komt dit uit in de samenwirking van zowel individuele economisten als ook van groeperingen in de bevolking en partijen bij het ontwerpen van de politiek van wederopbouw van het land na de Tweede Wereldoorlog. Ofschoon hieruit veel goeds is voortgekomen, dient men zich hier ook voor overdrijving te hoeden; het is te hopen dat de belangstelling voor de nog wel bestaande sociale noden er niet door wordt verdreven. Evenzeer is het echter duidelijk dat de daartoe een halve eeuw geleden aanbevolen middelen thans veel minder overtuigde aanhangers hebben en dat het initiatief hier eerder bij de psychologisch en sociologisch ingestelde hervormers is komen te liggen. De taak van de econoom is hierbij, ook wanneer het initiatief niet op zijn terrein zou terugkeren, in één opzicht nog steeds belangrijk genoeg: hij moet er op toezien dat men de economische wetten niet over het hoofd ziet. Bij de veel gecompliceerder verhoudingen van thans is dat een zwaarder taak geworden dan het een eeuw lang was. 
$\mathrm{Er}$ is natuurlijk ook het sociale vraagstuk van de positie van de vrouw. Hier treffen wij in het bijzonder in een zeer lange periode steeds weer de actieve medewerking van Anna Polak aan.

Tenslotte loont het de moeite nog afzonderlijk de vraag te stellen, in het voorafgaande reeds genoemd en ten dele ook reeds beantwoord: welke invloeden van grote persoonlijkheden bespeuren wij bij het doorbladeren van de honderdjarige Economist? Onbetwist zal blijven dat daarbij de figuur van Pierson in de eerste plaats moet worden genoemd. Gedurende vele jaren treffen wij zijn heldere bijdragen aan, die de zuiver wetenschappelijke geest zo duidelijk weerspiegelen en zijn groot talent demonstreren.

Met het gemak van degene die enerzijds de vraagstukken inderdaad geheel begrepen heeft en anderzijds meester over zijn woorden is legt hij de betekenis uit van bv. de waarderingsproblemen in een socialistische maatschappij. Met de onbevooroordeeldheid van de onderzoeker die het om het begrijpen voorai te doen is schetst hij de verschillende soorten socialisme. Het. treft ons hoe bij de discussie omtrent het berekenen van het maatschappelijk inkomen in een socialistische wereld de vraagstukken aanduidt die ook heden actualiteit hebben nu we de gegevens min of meer bezitten die toen slechts veronderstellenderwijs aan de berekening ten grondslag werden gelegd. De moeilijkheden van de statisticus van vandaag worden er voortreffelijk in benaderd.

Wanneer Pierson in het jaar 1910 niet langer tot de levenden behoort, zijn het zijn door C. A. Verrijn Stuart bijeengebrachte Verspreide Geschriften, die uitvoerig besproken worden door Van Blom, waarbij ook deze laatste nog eens zijn visie op de grote leermeester geeft. Hij wijst er op dat Pierson, ofschoon onder de invloed van zowel de Engelse als de Duitse wetenschap staande, zijn eigen visie heeft weten te ontwikkelen.

Hij was geen dogmaticus en heeft zijn mening ook wel eens durven wijzigen. Zeer juist was, volgens Van Blom, Piersons visie op de taak van de geschiedenis enerzijds en de economische theorie anderzijds bij het economisch onderzoek. Van Blom meent echter wel - en dat is voor ons onderwerp van bijzondere betekenis - dat Pierson wellicht nog iets te weinig heeft van een sociale dynamica, een leer van de ontwikkeling der maatschappelijke verhoudingen. 
Naast Pierson moet als grote figuur van dit tijdvak uiteraard C. A. Verrijn Stuart worden genoemd, van wiens hand De Economist ook een indrukwekkende reeks bijdragen heeft mogen zien, zij het dat deze wellicht nog iets meer dan die van Pierson de specialisatie van de economische theorie demonstreert. Mede daardoor is de directe aanraking met het sociale vraagstuk bij Verrijn Stuart minder duidelijk. Zij is er niettemin, daar waar Stuart over de werkloosheid schrijft, zoals in 1909 en deelnam aan de discussie over de achturendag in 1924. Het is bekend dat Verrijn Stuart daarbij steeds het non-interventionisme heeft bepleit en van geloof heeft getuigd in de werking der vrije economische krachten ook ten aanzien van het loon. Gingen zijn opvattingen daardoor enerzijds wel sterk in tegen datgene wat veel socialistisch georiënteerde figuren hebben bepleit, van de zijde dezer laatsten is toch veelal vergeten welke fundamentele functie het loon heeft in het evenwicht van een klein land te midden van een omringende wereld. Zou men in de huidige termen geneigd zijn te stellen, dat op korte termijn de regulerende functie van het loon vermoedelijk sterk achterblijft bij wat Verrijn Stuart haar toeschrijft, op langer zicht is het niettemin aannemelijk dat deze fundamentele krachten niet straffeloos kunnen worden verwaarloosd.

Als typische exponent van een meer sociaal gerichte belangstelling kan ook nog in de 20 e eeuw C. F. Stork worden genoemd, die in de jaargangen 1907 en 1908 over loonregelingen heeft geschreven, waarbij hij het grote voordeel had in zijn eigen fabriek de praktijk van zijn denkbeelden te kunnen demonstreren. Dit zal niet veel schrijvers in De Economist gegeven zijn geweest! Daarnaast moge ook de figuur van onze oud-collega Van Blom worden gememoreerd, die door zijn bekende uiteenzettingen na 1920 over de socialisatie veel heeft bijgedragen tot een overbrugging van tegenstellingen, die toen zeer sterk waren en langzamerhand aan scherpte aanzienlijk hebben verloren.

De grote socialistische en kerkelijke figuren komt men slechts een enkele maal in De Economist tegen. Wij vermeldden reeds Wibaut. Men zal ook mannen als Bonger, Van der Waerden en Van Gelderen slechts zelden aan het woord vinden. Ten dele verklaart zich dit uit de verenging van het terrein van De Economist waarover wij reeds spraken. De meer sociologisch of politiek georiënteerden vonden hun plaatsruimte in de nieuwere 
tijdschriften, waarvan we er reeds enkele noemden. Ook is het aantal dezer figuren dat nog tijd vindt voor wetenschappelijk werk in een klein land als het onze niet groot. Terecht kwam een studie als die van Van der Wijk over de inkomstenverdeling daarentegen wel in De Economist.

Tenslotte - hiermede mogen wij onze bijdrage tevens besluiten - is het voor de tijdgenoot moeilijker te onderkennen of zich reeds weer figuren aan het ontwikkelen zijn waarvan de kroniekschrijver later zal zeggen: hij behoort in de rij der grootsten. Deze rij pleegt zich niet continu voort te zetten; zij wordt door lacunes onderbroken en zij heeft het avontuurlijke van het niet aan de statistiek toebehorende terrein. 